\title{
Smart energy: where do we stand and where should we go?
}

\author{
Johann Kranz • Lutz M. Kolbe • Chulmo Koo • \\ Marie-Claude Boudreau
}

Published online: 23 January 2015

(C) Institute of Information Management, University of St. Gallen 2015

\section{Introduction}

Although public concern about environmental issues has been growing, the global efforts towards greater environmental sustainability have not been able to stabilize-let alone decrease - the level of GHGs in the atmosphere (IPCC 2013). Still worse, in 2013 the level of carbon dioxide (the main GHG produced by burning fossil fuels such as coal and oil) in the atmosphere surged at its fastest rate in 30 years (IPCC 2013). Annually, about 50 billion tons of additional carbon dioxide are emitted (The Economist 2014). There is a consensus among academics that, by 2100 , in order to avoid "dangerous anthropogenic interference with the climate system" (UNFCCC 1992), the global mean temperature must not increase more than two degrees Celsius above pre-industrial levels. To stabilize carbon dioxide concentration at this level,

\section{J. Kranz $(\square)$}

Chair of Management Information Systems and Methods, University of Göttingen, Platz der Göttinger Sieben 5,

37073 Göttingen, Germany

e-mail: jkranz@uni-goettingen.de

\section{M. Kolbe}

Chair of Information Management, University of Göttingen,

Platz der Göttinger Sieben 5, 37073 Göttingen, Germany

e-mail: 1kolbe@uni-goettingen.de

\section{Koo}

College of Hotel \& Tourism Management, Kyung Hee University, 26 Kyunghee-dearo, Dongdaemun-gu, Seoul 130-701, South Korea e-mail: helmetgu@khu.ac.kr

\section{M.-C. Boudreau}

Department of Management Information Systems, Terry College of Business, University of Georgia, 312 Brooks Hall, 310 Herty Drive, Athens, GA 30602, USA

e-mail: mcboudre@uga.edu emissions must be reduced by around 40 to $70 \%$ (compared to 2010) by 2050 and close to zero by 2100 (IPCC 2014a). Currently, however, it appears extremely unlikely that the global community will succeed in effectively curbing GHG emissions fast enough to achieve the two degrees Celsius goal.

Our economies are still heavily dependent on fossil fuels, and as long as increasing economic prosperity goes along with increasing levels of GHG emissions (von Weizsäcker, Hargroves, Smith, Desha, and Stasinopoulos 2009, pp. 17), these emissions will almost certainly not decline as much as needed. To break this vicious cycle, we have to identify ways to increase carbon productivity (using energy more efficiently while sustaining economic growth), consume less energy (eco-effectivity and eco-sufficiency), and decrease our dependency on fossil fuels by using renewable energy sources (Hoffert et al. 2002; McKinsey Global Institute 2008; von Weizsäcker et al. 2009). Correspondingly, Sarkis, Koo, and Watson (2013) emphasize the need to find a synergistic win-win relationship between economic growth and green growth.

The largest proportion (49\%) of GHG emissions are caused by the energy supply sector (IPCC 2014b). Due to a higher energy demand and a larger share of coal in the global fuel mix, GHG emissions associated with the energy supply sector increased more rapidly between 2000 and 2010 than in the three previous decades (IPCC 2014a). Seventy percent of the energy supply sector's GHG emissions are caused by electricity and heat generation, the largest polluter of which is in the electricity sector. Therefore, many countries have been striving to make their electricity systems more renewablesbased and "intelligent." Intelligent (or smart) systems often involve the deployment of information and communication technologies (ICTs) to allow for electricity systems to be used as efficiently as possible. 
ICTs have been leveraged in making many areas "smarter," including supply chains, operations, transportation, buildings, and grids. ICTs indeed have great potential to lower carbon emissions within each of them (Climate Group 2008). In fact, both information systems (IS) and information technology (IT) have been leveraged to support many green developments and sustainability initiatives. Like other scholars, we make a clear distinction between Green IS and Green IT. With Green IT, we refer to the hardware and other infrastructure that can be better managed and designed from an environmental perspective (e.g., Watson, Boudreau, and Chen 2010a; Sarkis et al. 2013). Green IS, however, is the integrated and cooperating set of people, processes, software, and information technologies to support individual, organizational, or societal goals, making Green IS more encompassing than Green IT (Watson et al. 2010a).

Energy informatics (Watson et al. 2010a), which highlights the potential of Green IS in the context of energy distribution and consumption systems, has emphasized the need for regulations to pave the way to practical solutions in the energy sector. Regulations are called for to provide the "right" incentives to all energy-related market players. Germany, for one, demonstrates impressively how misaligned incentives and inaccurate market design can lead to spending huge amounts on renewables ( $€ 16$ billion/year) while GHG emissions keep growing. In Germany's case, electricity generated from renewables gets priority on the grid, such that especially solar power seizes market share during the most profitable times of day (around noon). The result is that operating conventional power plants is becoming less profitable and predictable. Additionally the collapsed prices for carbon emissions provided by the EU's cap-and-trade emissions trading scheme have made coal-fired power plants more profitable than lesspolluting energy sources such as gas. A German utility, for instance, would have lost $€ 11.70$ per MW on average at the beginning of November 2012 when burning gas, but would have earned $€ 14.22$ per MW when burning coal instead (The Economist 2013).

Similar examples of well-intentioned regulations leading to unwelcome outcomes can be found all around the world. Because of the electricity system's complexity, a large variety of environmental factors (which often have significant impacts) must be considered when providing incentives for energy efficiency and renewable energy sources. Accordingly, IS research needs to consider the idiosyncrasies of how energy markets and systems function and how they are regulated in order to deliver relevant outcomes. Major IS and IT academic societies, journals, and special interest groups (SIGs) on Green IS and IT should increase the voice of green necessities and inspire IS researchers and practitioners to undertake the critical role of both Green IS and IT through goods manufacturing and services operating embedded in the life cycles of materials, manufacturing systems, and public infrastructure (Ryoo and Koo 2013; Sarkis et al. 2013).

Correspondingly, the aim of this special issue is to advance research on smart energy with a particular focus on interdisciplinary perspectives offering viable new insights to scholars, policy makers, regulators, and business decision makers alike. This special issue understands smart energy as the use of ICTs in energy generation, storage, transmission, and consumption, aiming at increasing efficiency, encouraging eco-friendly behavior, and decreasing the emission of GHG. Thus, smart energy research is a component of the energy informatics framework proposed by Watson et al. (2010a).

\section{Where do we stand?}

Five years have passed since Watson, Boudreau, and Chen (2010a) and Melville (2010) called for IS research on energy informatics and environmental sustainability in the MIS Quarterly. Since then we have witnessed a steady increase of studies, conference tracks, journal special issues, workshops, and researchers addressing the question of how IS can contribute to decreasing the consumption of natural resources and emission of hazardous substances. Given the importance of the energy supply sector, the impact and potential of Green IS is enormous, making it one of the major future topics in IS research (Baker et al. 2011; Dao, Langella, and Carbo 2011). For example, according to estimates, increased use of ICTs in transportation, building, and electricity grids could decrease total GHG emissions by $15 \%$ in 2020 (Climate Group 2008).

Green IS addresses issues related to the IS use of individuals, groups, organizations, and societies that help ecosustainable practices emerge and diffuse (Chen, Watson, Boudreau, and Karahanna 2010; Dedrick 2010; Ijab, Molla, and Cooper 2012; Hilpert, Kranz, and Schumann 2013). The impact of Green IS on eco-sustainability - and with it the literature on Green IS - can be categorized into three effects (Köhler and Erdmann 2004; Hilty et al. 2006; Dedrick 2010):

(1) First order effect: Direct impacts on the environment due to the physical existence and use of IT, often labeled as “Green IT" (e.g., Dao et al. 2011; Molla 2009; Murugesan 2008; Karanasios, Cooper, Deng, Molla, and Pittayachawan 2010; Schmidt, Erek, Kolbe, and Zarnekow 2011; Opitz, Thies, Erek, Kolbe, and Zarnekow 2013; Reiter, Fettke, and Loos 2013; Ryoo and Koo 2013; Koo and Chung 2014)

(2) Second order effect: Enabling effects of ICTs in other sectors such as energy, logistics, mobility, and manufacturing that lead to more sustainable business operations, often labeled as "Green (by) IS" (Watson et al. 2010a; Watson, Boudreau, Li, and Levis 2010b; Butler 2011; Kranz and Picot 2011a; Sarkis, Zhu, and Lai 2011; 
Loeser, Erek, and Zarnekow 2012; Brandt, Feuerriegel, and Neumann 2013; Busse et al. 2013; Hilpert et al. 2013; Stiel and Teuteberg 2013; Wunderlich et al. 2013; Koo, Chung, and Ryoo 2014)

(3) Third order effect: Systemic effects of ICTs causing medium- or long-term changes of behavior and economic structures towards more eco-sustainable practices, often labeled as "Green IS" (Watson et al. 2011; e.g., Loock et al. 2013; Seidel et al. 2013)

To analyze where the field is going, we have conducted a literature review of articles in major IS journals. Our search included the AIS basket of eight leading IS journals (European Journal of Information Systems, Information Systems Journal, Information Systems Research, Journal of AIS, Journal of Information Technology, Journal of MIS, Journal of Strategic Information Systems, and MIS Quarterly), Electronic Markets, and Business \& Information Systems Engineering. We selected research papers focusing on smart energy that were published after the seminal works of Watson et al. (2010a) and Melville (2010). We used the Web of Science, Business Source Premier, and the AIS Electronic Library to search for the keywords "Green Information System", "Green IS", "Smart Grid", "Smart Energy", "Energy Informatics", and "Environmental Sustainability". Although Green IT (first-order effect) is an important field in Green IS, our search focused on the second and third order effects of Green IS in smart energy contexts in congruence with this special issue's aim. Table 1 provides details about the articles and how they can be categorized.

Our literature review reveals that the extant literature on smart energy has predominantly focused on topics related to energy consumption of private users as well as individuals and groups in organizations. Furthermore, prior literature is dominated by conceptual and analytical works. Few studies have employed a design-oriented approach to develop IS artifacts that actually have an impact on environmental sustainability. A particularly striking result of our review is the monothematic focus on energy consumption of most smart energy research published in IS journals, while in other outlets we find a number of studies on ICT's role in smart energy, addressing issues related to energy generation, transmission, storage, and consumption (e.g., Kranz and Picot 2011b; Catulli and Fryer 2012; Römer, Reichhart, Kranz, and Picot 2012; Gorsevski et al. 2013; Wunderlich et al. 2013; Schmidt, Eisel, and Kolbe 2014).

This raises the question of why these papers have not been published in IS outlets. The most obvious reason is that the focus of these studies is not primarily on information systems. Moreover, research on smart energy is necessarily inter- (or trans-) disciplinary, which seems not to fit into the tradition of IS journals (Malhotra, Melville, and Watson 2013). For these reasons, we edited this special issue to give cross-cutting research on smart energy a platform in an IS journal. According to our view, research on IS in general and Green IS in particular should move beyond a "general utility perspective" (von Brocke and Seidel 2012, p. 294) and demonstrate its concrete value for environmental sustainability.

\section{Where should we go from here?}

As outlined above, the IS community has taken up the issue of environmental sustainability, and Green IS has established itself as a key area of information systems research. As our literature review has shown, however, the field must move forward to have a real impact on the pressing issue of climate change and environmental degradation (Malhotra et al. 2013). Many researchers in the field of Green IS, for instance, have proposed frameworks, methods, and prototypes for increasing energy efficiency or inducing behavioral changes. We do not know exactly how many of them have been put into practice, but we suppose not too many. This way, many good ideas and insights get lost.

Consequently, from an outsider's perspective, the value of IS research in solving one of the most critical problems of humankind is virtually imperceptible. We reckon, therefore, that Green IS needs to show more of its "specific utility". Moreover, Green IS researchers should make their voices heard both within and outside the IS community. They should guide political and regulatory decision-making processes and engage in industry consortiums or even entrepreneurial endeavors. Further, academics in Green IS should participate in inter- (and trans-) disciplinary research collaborations, as impactful solutions in the field of smart energy are inevitably involving a wide range of disciplines (e.g., engineering, economics, political sciences, environmental sciences, sociology, geology) (Elliot 2011).

To encourage more of this interdisciplinary and impactful research, however, IS journals must open themselves to alternative research methods and topics. Malhotra et al. (2013) have made specific suggestions about how IS journals could embrace more problemoriented research, which we explicitly support. In a nutshell, they claim that journals should create special editorial teams for some time that serve as "gate openers" for impactful (Green IS) research. These teams should carefully balance the impact of an article and its theoretical contribution. As would be expected, Green IS research must still adhere to the high scientific standards of our discipline. However, the societal impact should become a more important decision criterion in the review process to make our discipline more relevant and visible. 


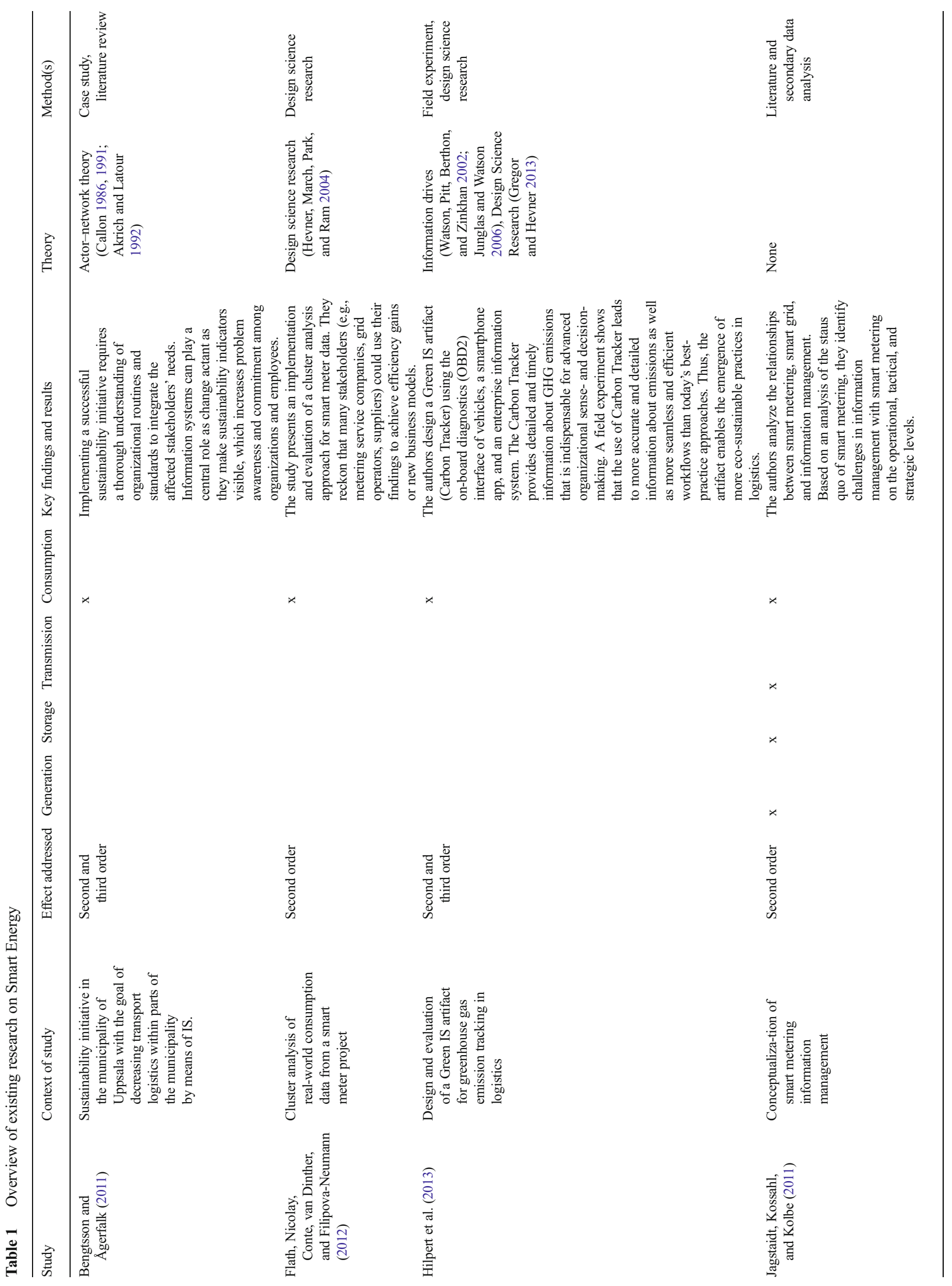




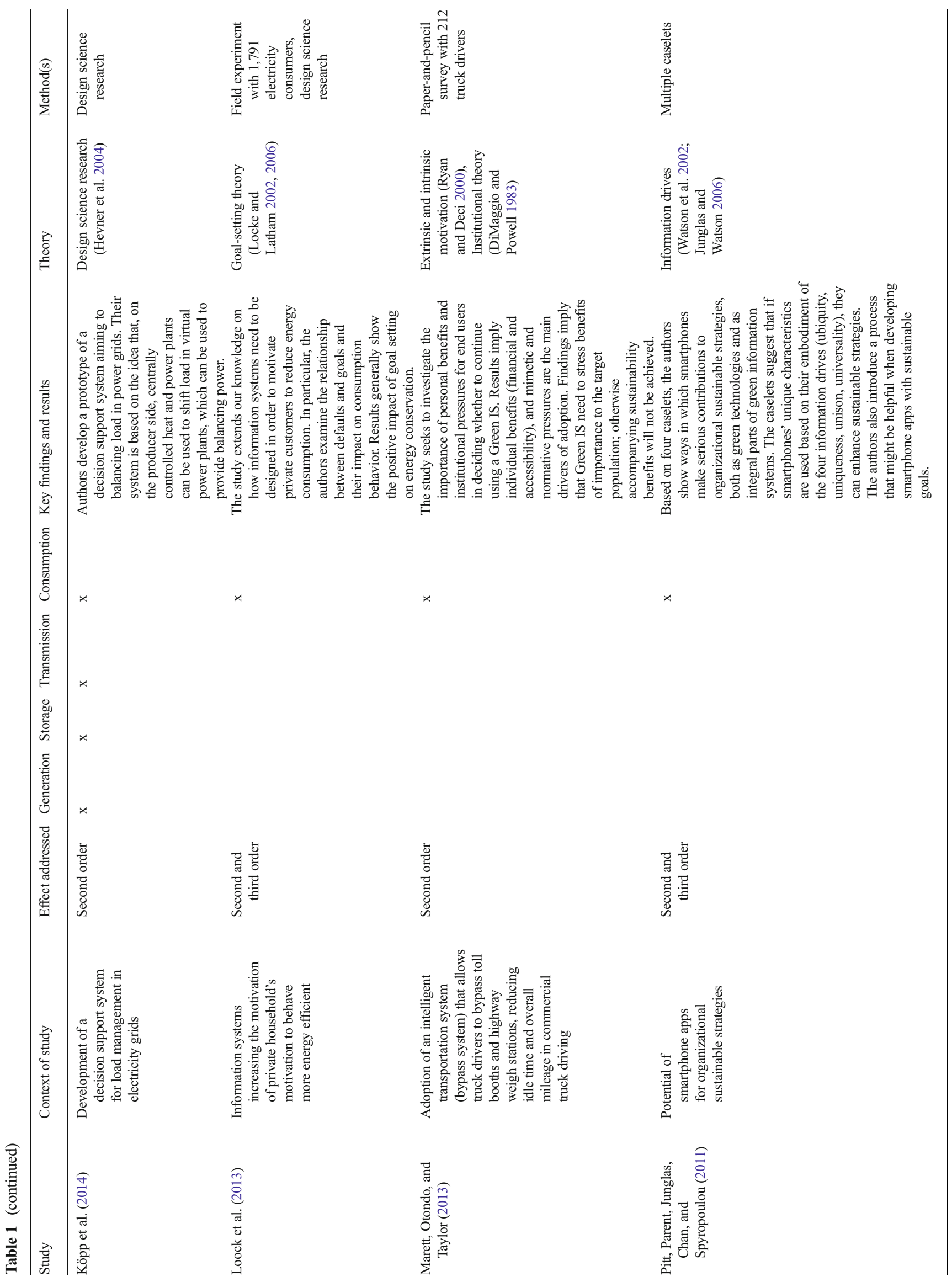




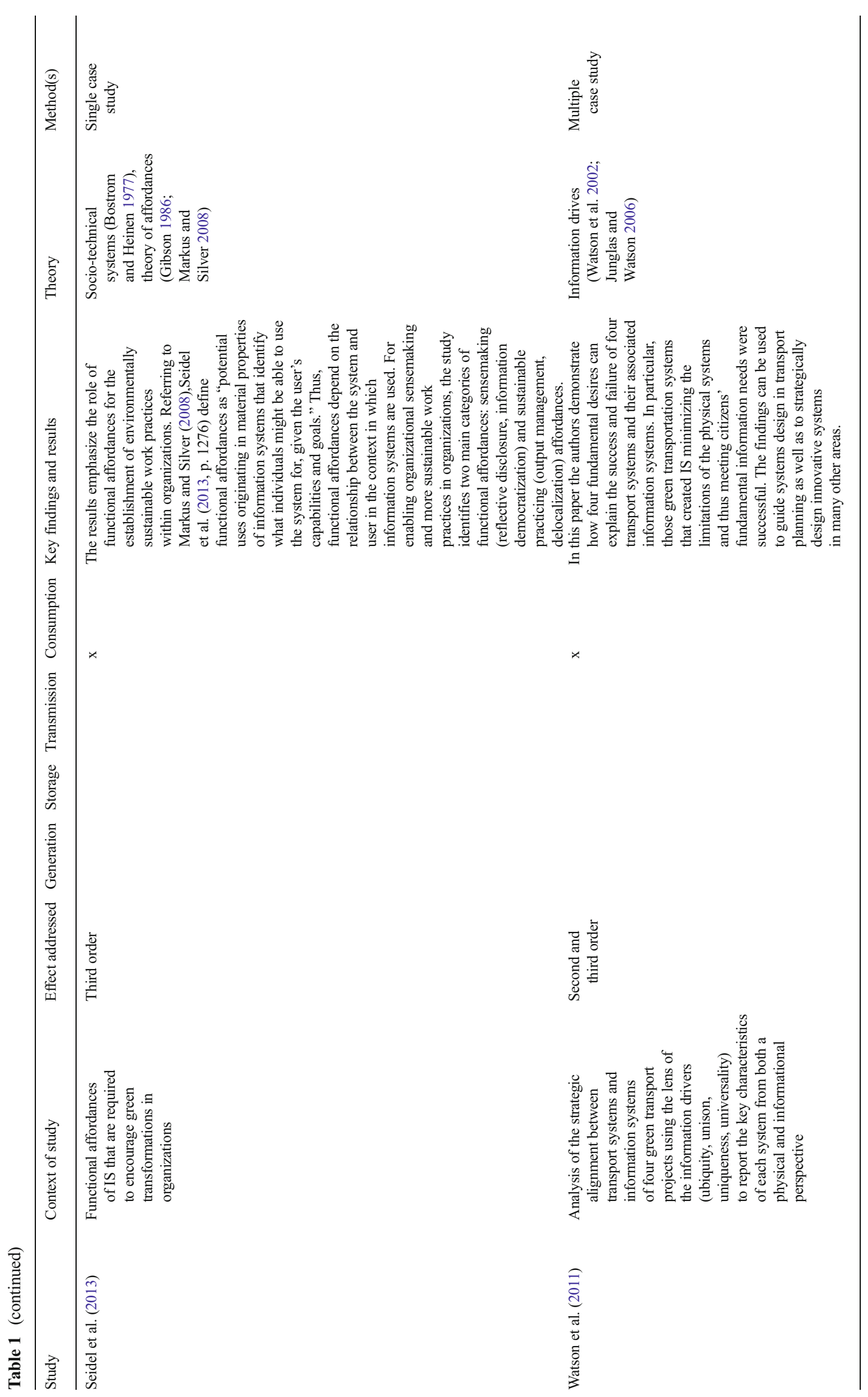


We see manifold opportunities for Green IS research, particularly in smart energy, intersecting with other upto-date topics in IS research. As ICTs are becoming increasingly powerful, small, and efficient, the number of products and services in which they are embedded is rapidly growing. Also in the energy sector, ICTs enable and trigger service innovations that transform traditional business models. We see energy suppliers using ICT to move away from a goods-oriented business model (producing and selling energy) towards more service- or solution-based business models such as managing energy production and consumption or offering home automation services (Wunderlich et al. 2013).

Beyond that, ICT is embedded into physical goods to make them "smarter" and uniquely identifiable via the Internet ("Internet of Things") (Nambisan, 2013; Yoo, 2010). Sensor and actuator networks are integrated with the physical electricity grid infrastructure to socalled cyber physical systems with the aim of increasing reliability, efficiency, and environmental sustainability. In our view, many different streams of IS research (e.g., decision analytics and big data, design science, security and privacy, human-computer interaction, service science, economics of IS, technology acceptance) can contribute to analyzing, designing, or improving smart-energy innovations. We also see potential for IS scholars to engage in issues related to the regulation and design of energy markets. In future energy systems, a huge number of decentralized actors and components will exchange information, and they need to be coordinated to increase total factor productivity. This raises a variety of issues such as optimal market design, data security and privacy, and data access and control rights, which need to consider the special structures of energy markets (see Kranz and Picot 2011b).

\section{Papers within this special issue}

In this special issue on smart energy, three papers are presented, two of which employ a qualitative approach and one paper uses a quantitative survey research approach. All papers address the second and third order effects of Green IS. They analyze how the enabling effect of ICT in the energy sector might unfold and how ICT can be used to significantly transform the way energy is generated, transmitted, consumed, and stored.

The first paper ("Adoption of Smart Grid Technologies by Electric Utilities: Factors Influencing Organizational Innovation in a Regulated Environment") leverages semistructured interviews to present a model identifying how technology, organizational and environmental factors, and the policy and regulatory environment influence the adoption of smart grid technologies by energy utilities. The second paper ("What are the main barriers to smart energy information systems diffusion?") uses a grounded theory approach to specifically look at the factors that hamper the diffusion of electricity and information networks that connect energy generators, distributors, and consumers. The third paper ("Smart Energy for Robinson Crusoe: An Empirical Analysis of the Adoption of IS-Enhanced Electricity Storage Systems") investigates the impact of diverse factors on private households' adoption of decentralized energy storage systems, collecting data of energy "prosumers" and consumers via an online survey.

All papers of this special issue contribute new insights that we expect will be useful for scholars, policy makers, regulators, and business practitioners alike. A short summary of each article follows.

Jason Dedrick, Murali Venkatesh, Jeffrey M. Stanton, You Zheng, and Angela Ramnarine-Rieks ("Adoption of Smart Grid Technologies by Electric Utilities: Factors Influencing Organizational Innovation in a Regulated Environment") address the question of why adoption rates of smart grid technologies are still low. Based on 15 interviews with 12 U.S. utilities, they investigate which organizational and regulatory factors hamper the diffusion of potentially disruptive technologies within a regulated industry. From a utility's perspective, they identify that new skills, top management support, and a culture of innovation are needed to address the challenges outlined above. For policy and regulation, the findings suggest that new regulatory approaches that spur retail competition and delink revenues from the volume of power sold would create a more innovation-friendly environment in the energy sector.

Fabian Schwister and Marina Fiedler ("What are the main barriers to smart energy information systems diffusion?") specifically analyze barriers that impede the dissemination of information and communication technologies in energy systems that enable all actors and components to bidirectionally communicate with each other through electricity and information networks. Based on 23 interviews with various stakeholders from the energy sector, they find that adoption costs, switching costs, and the collective action dilemma are the main barriers. They conclude that the majority of the issues identified could be solved if universally accepted interfaces, messaging and control protocols, and standards were in place. Regulatory and legal frameworks should support interoperability by establishing procedures regarding data management and communication. Moreover, the authors claim that a lack of profitable business cases exacerbate these barriers. 
Benedikt Römer, Philipp Reichhart, and Arnold Picot ("Smart Energy for Robinson Crusoe: An Empirical Analysis of the Adoption of IS-Enhanced Electricity Storage Systems") focus on the adoption of energy technologies in private households. Specifically, they investigate consumers' intention to invest in physical electricity storage systems which are controlled by ICT and enable decoupling the generation and consumption of electricity generated by prosumers. Based on a survey with 339 German respondents, they identify that social norms, affinity towards autarky, and concerns about the security of energy supply are the main drivers for private households' investment in electricity storage systems. Therefore, they suggest granting private households complete control rights over the storage systems to increase their autarky and their household's security of supply.

The three papers address pressing questions, which at the same time raise new ones. We therefore hope that this special issue will encourage further research on these questions and adjacent topics. We believe that the diffusion of ICTs in the energy supply sector will depend heavily on how the regulation of energy markets adapts to the new realities and challenges of climate change, environmental degradation, and economic prosperity. As energy markets are highly complex and subject to a multitude of external influences, their market design is all the more important. Market players need to be given adequate incentives to optimize social welfare and environmental sustainability. Furthermore, utilities active in the regulated transmission and distribution segments need to be provided with some degree of planning certainty, as investments in physical infrastructure are long dated. In the other segments of the energy market though, competition that takes the cost of avoiding GHG emissions into account should be promoted. Because we have reason to believe that if policy and regulation provide a sound regulatory framework rewarding the reduction of GHG emissions, organizations and households have more incentive to invest in green technologies that mitigate climate change.

At the close of this preface, we want to thank the reviewers for their time and effort, Editor-in-Chief Rainer Alt and the editorial team for giving us the chance to edit this special issue, and the editorial office of Electronic Markets for their great support.

\section{References}

Akrich, M., \& Latour, B. (1992). A summary of a convenient vocabulary for the semiotics of human and nonhuman assemblies. In W. E. Bijker \& J. Law (Eds.), Shaping technology / building society: Studies in sociotechnical change (pp. 256-264). Cambridge: MIT Press.
Baker, J., Avital, M., Davis, G., Land, F., Morgan, H., \& Wetherbe, J. C. (2011). ICIS 2010 panel report: technologies that transform business and research: lessons from the past as we look to the future. Communications of the Association for Information Systems, 28(1), 497-508.

Bengtsson, F., \& Ågerfalk, P. J. (2011). Information technology as a change actant in sustainability innovation: insights from Uppsala. The Journal of Strategic Information Systems, 20(1), 96-112.

Bostrom, R. P., \& Heinen, J. S. (1977). MIS problems and failures: a socio-technical perspective part I: the causes. MIS Quarterly, 1(3), $17-32$.

Brandt, T., Feuerriegel, S., \& Neumann, D. (2013). Shaping a sustainable society: How information systems utilize hidden synergies between green technologies. Milan: Proceedings of the 34th International Conference on Information Systems (ICIS).

Busse, S., El Khatib, V., Brandt, T., Kranz, J., \& Kolbe, L. M. (2013). Understanding the role of culture in eco-innovation adoption - An empirical cross-country comparison. Milan: Proceedings of the 34th International Conference on Information Systems (ICIS).

Butler, T. (2011). Compliance with institutional imperatives on environmental sustainability: building theory on the role of Green IS. The Journal of Strategic Information Systems, 20(1), 6-26.

Callon, M. (1986). Some elements of a sociology of translation: Domestication of the scallops and the fishermen of St. Brieuc Bay. In J. Law (Ed.), Power, action, and belief: A new sociology of knowledge? (pp. 196-233). London, Boston, Henley: Routledge \& Kegan Paul.

Callon, M. (1991). Techno-economic networks and irreversibility. In J. Law (Ed.), A sociology of monsters. Essays on power, technology and domination (pp. 132-165). London, New York: Routledge.

Catulli, M., \& Fryer, E. (2012). Information and communication technology-enabled low carbon technologies. Journal of Industrial Ecology, 16(3), 296-301.

Chen, A. J., Watson, R. T., Boudreau, M.-C., \& Karahanna, E. (2010). An institutional perspective on the adoption of Green IS \& IT. Australasian Journal of Information Systems, 17(1), 23-45.

Climate Group. (2008). SMART 2020: Enabling the low carbon economy in the information age. Retrieved from http://www.gesi.org/ LinkClick.aspx?fileticket=tbp5WRTHUoY\%3d\&tabid=60

Dao, V., Langella, I., \& Carbo, J. (2011). From green to sustainability: information technology and an integrated sustainability framework. The Journal of Strategic Information Systems, 20(1), 63-79.

Dedrick, J. (2010). Green IS: concepts and issues for information systems research. Communications of the Association for Information Systems, 27(1), 173-184.

DiMaggio, P. J., \& Powell, W. W. (1983). The iron cage revisited: institutional isomorphism and collective rationality in organizational fields. American Sociological Review, 48(2), 147-160.

Elliot, S. (2011). Transdisciplinary perspectives on environmental sustainability: a resource base and framework for IT-enabled business transformation. MIS Quarterly, 35(1), 197-236.

Flath, C., Nicolay, D., Conte, T., van Dinther, C., \& Filipova-Neumann, L. (2012). Cluster analysis of smart metering data. Business and Information Systems Engineering, 4(1), 31-39.

Gibson, J. J. (1986). The ecological approach to visual perception. Hillsdale: Lawrence Erlbaum Associates.

Gorsevski, P. V., Cathcart, S. C., Mirzaei, G., Jamali, M. M., Ye, X., \& Gomezdelcampo, E. (2013). A group-based spatial decision support system for wind farm site selection in Northwest Ohio. Energy Policy, 55, 374-385.

Gregor, S., \& Hevner, A. R. (2013). Positioning and presenting design science research for maximum impact. MIS Quarterly, 37(2), 337355.

Hevner, A. R., March, S. T., Park, J., \& Ram, S. (2004). Design science in information systems research. MIS Quarterly, 28(1), 75-105. 
Hilpert, H., Kranz, J., \& Schumann, M. (2013). Leveraging Green IS in logistics. Business and Information Systems Engineering, 4(1), 315325 .

Hilty, L. M., Arnfalk, P., Erdmann, L., Goodman, J., Lehmann, M., \& Wäger, P. A. (2006). The relevance of information and communication technologies for environmental sustainability - a prospective simulation study. Environmental Modelling \& Software, 21(11), $1618-1629$.

Hoffert, M., Caldeira, K., Benford, G., Criswell, D., Green, C., Herzog, H., \& Wigley, T. (2002). Advanced technology paths to global climate stability: energy for a greenhouse planet. Science, 298(5595), 981-987.

Ijab, M., Molla, A., \& Cooper, V. (2012). Green information systems (Green IS) practice in organisation: Tracing its emergence and recurrent. Seattle: Proceedings of the 18th Americas Conference on Information Systems (AMCIS).

IPCC. (2013). Climate change 2013: The physical science basis. New York: Cambridge Univ Press.

IPCC. (2014a). Greenhouse gas emissions accelerate despite reduction efforts - Many pathways to substantial emissions reductions are available. Retrieved from http://ipcc.ch/pdf/ar5/pr_wg3/20140413 pr_pc_wg3_en.pdf

IPCC. (2014b). Climate change 2014: Mitigation of climate change. Cambridge, New York: Cambridge University Press.

Jagstaidt, U., Kossahl, J., \& Kolbe, L. M. (2011). Smart metering information management. Business and Information Systems Engineering, 3(5), 323-326.

Junglas, I., \& Watson, R. T. (2006). The u-constructs: four information drives. Communications of the Association for Information Systems, 17(1), 26.

Karanasios, S., Cooper, V., Deng, H., Molla, A., \& Pittayachawan, S. (2010). Antecedents to greening data centres: A conceptual framework and exploratory case study. Brisbane: Proceedings of the 21st Australasian Conference on Information Systems (ACIS).

Köhler, A., \& Erdmann, L. (2004). Expected environmental impacts of pervasive computing. Human and Ecological Risk Assessment: An International Journal, 10(5), 831-852.

Koo, C., \& Chung, N. (2014). Examining the eco-technological knowledge of smart Green IT adoption behavior: a self-determination perspective. Technological Forecasting and Social Change, 88, 140 155.

Koo, C., Chung, N., \& Ryoo, S. Y. (2014). How does ecological responsibility affect manufacturing firms' environmental and economic performance? Total Quality Management and Business Excellence, 25(9-10), 1171-1189.

Köpp, C., von Mettenheim, H.-J., \& Breitner, M. H. (2014). Decision analytics with heatmap visualization for multi-step ensemble data an application of uncertainty modeling to historical consistent neural network and other forecasts. Business and Information Systems Engineering, 6(3), 131-140.

Kranz, J., \& Picot, A. (2011a). Why are consumers going green? The role of environmental concerns in private green-is adoption. Helsinki: Proceedings of the 19th European Conference on Information Systems (ECIS).

Kranz, J., \& Picot, A. (2011b). Towards an end-to-end smart grid - overcoming bottlenecks to facilitate competition and innovation in smart grids. Communications of the National Regulatory Research Institute, 1-38.

Locke, E. A., \& Latham, G. P. (2002). Building a practically useful theory of goal setting and task motivation: a 35-year odyssey. American Psychologist, 57(9), 705-717.

Locke, E. A., \& Latham, G. P. (2006). New directions in goal-setting theory. Current Directions in Psychological Science, 15(5), 265268.

Loeser, F., Erek, K., \& Zarnekow, R. (2012). Towards a typology of Green IS strategies: Insights from case study research. Orlando:
Proceedings of the 33rd International Conference on Information Systems (ICIS).

Loock, C., Staake, T., \& Thiesse, F. (2013). Motivating energy-efficient behavior with Green IS: an investigation of goal setting and the role of defaults. MIS Quarterly, 37(4), 1313-1332.

Malhotra, A., Melville, N. P., \& Watson, R. T. (2013). Spurring impactful research on information systems for environmental sustainability. MIS Quarterly, 37(4), 1265-1274.

Marett, K., Otondo, R. F., \& Taylor, G. S. (2013). Assessing the effects of benefits and institutional influences on the continued use of environmentally munificient bypass systems in long-haul trucking. MIS Quarterly, 37(4), 1301-1312.

Markus, M. L., \& Silver, M. S. (2008). A Foundation for the study of IT Effects: a new look at desanctis and poole's concepts of structural features and spirit. Journal of the Association for Information Systems, 9(10/11), 609-632.

McKinsey Global Institute. (2008). The carbon productivity challenge: Curbing climate change and sustaining economic growth. Sydney: McKinsey Global Institute, McKinsey \& Company.

Melville, N. (2010). Information systems innovation for environmental sustainability. MIS Quarterly, 34(1), 1-21.

Molla, A. (2009). The extent of Green IT adoption and its drivers and inhibiting factors: an exploratory study. Journal of Information Science and Technology, 6(4), 1-21.

Murugesan, S. (2008). Harnessing Green IT: principles and practices. IT Professional, 10(1), 24-33.

Opitz, N., Thies, F., Erek, K., Kolbe, L. M., \& Zarnekow, R. (2013). Kennzahlenbasierte erfolgsmessung von Green IT-massnahmen Eine empirische analyse zum aktuellen stand in Forschung und Praxis. Leipzig: Proceedings of the 11th International Conference on. Wirtschaftsinformatik (WI2013).

Pitt, L. F., Parent, M., Junglas, I., Chan, A., \& Spyropoulou, S. (2011). Integrating the smartphone into a sound environmental information systems strategy: principles, practices and a research agenda. The Journal of Strategic Information Systems, 20(1), 27-37.

Reiter, M., Fettke, P., \& Loos, P. (2013). Towards a reference model for ecological IT service management. Milan: Proceedings of the 34th International Conference on Information Systems (ICIS).

Römer, B., Reichhart, P., Kranz, J., \& Picot, A. (2012). The role of smart metering and decentralized electricity storage for smart grids: the importance of positive externalities. Energy Policy, 50, 486-495.

Ryan, R. M., \& Deci, E. L. (2000). Intrinsic and extrinsic motivations: classic definitions and new directions. Contemporary Educational Psychology, 25(1), 54-67.

Ryoo, S., \& Koo, C. (2013). Green practices-IS alignment and environmental performance: the mediating effects of coordination. Information Systems Frontiers, 15(5), 799-814.

Sarkis, J., Zhu, Q., \& Lai, K.-H. (2011). An organizational theoretic review of green supply chain management literature. International Journal of Production Economics, 130(1), 1-15.

Sarkis, J., Koo, C., \& Watson, R. T. (2013). Green information systems \& technologies - this generation and beyond: introduction to the special issue. Information Systems Frontiers, 15(5), 695-704.

Schmidt, N.-H., Erek, K., Kolbe, L. M., \& Zarnekow, R. (2011). Examining the contribution of Green IT to the objectives of IT departments: empirical evidence from german enterprises. Australasian Journal of Information Systems, 17(1), 127-140.

Schmidt, J., Eisel, M., \& Kolbe, L. M. (2014). Assessing the potential of different charging strategies for electric vehicle fleets in closed transport systems. Energy Policy, 74, 179-189.

Seidel, S., Recker, J., \& von Brocke, J. (2013). Sensemaking and sustainable practicing: functional affordances of information systems in green transformations. MIS Quarterly, 37(4), 1275-1299.

Stiel, F., \& Teuteberg, F. (2013). Towards a conceptual framework for life cycle assessment in sustainable information systems management. 
Utrecht: Proceedings of the 21st European Conference on Information Systems (ECIS).

The Economist. (2013). Europe's dirty secret. The unwelcome renaissance. Retrieved from http:/www.economist.com/news/briefing/ 21569039-europes-energy-policy-delivers-worst-all-possibleworlds-unwelcome-renaissance

The Economist. (2014). Encouraging climate action: Try jam today. Retrieved from http://www.economist.com/news/briefing/ 21618682-policies-slow-down-warming-may-be-more-attractiveif-framed-ways-speeding-up-growth-try

UNFCCC. (1992). UN Framework Convention on Climate Change. Palais des Nations, Geneva. Retrieved from http://unfccc.int/ resource/docs/convkp/conveng.pdf

von Brocke, J., \& Seidel, S. (2012). Environmental sustainability in design science research: Direct and indirect effects of design artifacts. In K. Peffers, M. Rothenberger, \& B. Kuechler (Eds.), Design science research in information systems. Advances in theory and practice (pp. 294-308). Berlin: Springer.

von Weizsäcker, E., Hargroves, K., Smith, M., Desha, C., \& Stasinopoulos, P. (2009). Factor five: Transforming the global economy through $80 \%$ improvements in resource productivity. London: Earthscan.

Watson, R. T., Pitt, L. F., Berthon, P., \& Zinkhan, G. M. (2002). Ucommerce: expanding the universe of marketing. Journal of the Academy of Marketing Science, 30(4), 333-347.

Watson, R. T., Boudreau, M.-C., \& Chen, A. J. (2010a). Information systems and environmentally sustainable development: energy informatics and new directions for the IS community. MIS Quarterly, 34(1), 23-38.

Watson, R. T., Boudreau, M.-C., Li, S., \& Levis, J. (2010b). Telematics at UPS: en route to energy informatics. MIS Quarterly Executive, 9(1), $1-11$.

Watson, R. T., Boudreau, M.-C., Chen, A. J., \& Sepúlveda, H. H. (2011). Green projects: an information drives analysis of four cases. The Journal of Strategic Information Systems, 20(1), $55-62$.

Wunderlich, P., Kranz, J., Totzek, D., Veit, D., \& Picot, A. (2013). The impact of endogenous motivations on adoption of IT-enabled services: the case of transformative services in the energy sector. Journal of Service Research, 16(3), 356-371. 